\title{
Evaluation of p40 as a Myoepithelial Marker in Different Breast Lesions
}

\author{
Bence Kővária $^{a}$ A. Marcell Szász ${ }^{\mathrm{b}, \mathrm{c}}$ Janina Kulka ${ }^{\mathrm{b}}$ Zlatko Marušić $^{d}$

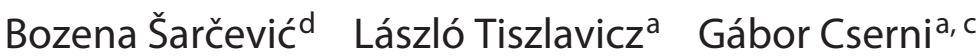 \\ ${ }^{a}$ Department of Pathology, University of Szeged, Szeged, ${ }^{b}$ Second Department of Pathology, Semmelweis \\ University, Budapest, and ' ${ }^{\circ}$ Department of Pathology, Bács-Kiskun County Teaching Hospital, Kecskemét, Hungary; \\ ${ }^{\mathrm{d}}$ Department of Pathology, University Hospital Center Sestre Milosrdnice, Zagreb, Croatia
}

\section{Key Words \\ Adenomyoepithelioma - Basal-like carcinoma - Breast . \\ Ductal carcinoma in situ - Immunohistochemistry . \\ Myoepithelial cells $\cdot$ p40 $\cdot$ p63 $\cdot$ Sclerosing lesions}

\section{Abstract}

Objective: The identification of myoepithelial cells (MEC) is a valuable clue in the differential diagnosis of breast lesions. A series of breast lesions with occasional absence of or decrease in the staining for some MEC markers was analyzed for the expression of a novel marker, p40, and results were compared to the p63 staining profile. Methods: Samples $(n=34)$ from patients with benign sclerosing lesions $(n=11)$, ductal carcinoma in situ $(n=13)$ and adenomyoepithelial lesions $(n=10)$ and associated normal breast tissues $(n=31)$ were selected to evaluate the differential expression of $\mathrm{p} 40$ and p63 using immunohistochemistry. Triple-negative, cytokeratin 5 (CK5)-expressing invasive breast carcinomas ( $\mathrm{n}=$ 19) were also assessed for p40 expression. Results: Normal structures showed similar diffuse and strong MEC positivity using p40 and p63 in all 31 cases. The two antibodies performed similarly in all 34 breast lesions acknowledged to present altered expression of MEC markers; focal losses of expression occurred in a parallel fashion. CK5-positive carci- nomas expressed p40 more frequently than p63 (18/19 vs. 8/19) and the staining was more marked. Conclusions: It seems that both antibodies can be used interchangeably for MEC identification, but show differences in the labeling at least in a subset of tumor cells in triple-negative carcinomas.

(c) 2015 S. Karger AG, Basel

\section{Introduction}

The tumor suppressor gene family p53 includes genes of transformation-related proteins TP53, TP63 and TP73, which are responsible for encoding transcription factor proteins labelled as tumor proteins p53, p63 and p73, respectively $[1,2]$.

The tumor suppressor p53 enforces its anti-oncogenic functions by arresting the cell cycle, initiating apoptosis and facilitating DNA repair through its effects on the transcription of other tumor suppressor genes $[3,4]$.

In contrast to the ubiquitous expression of $\mathrm{p} 53$, the expression of $\mathrm{p} 63$ and $\mathrm{p} 73$ is restricted to certain tissue types, but p63 and p73 share partially overlapping functions with p53 by upregulating numerous p53 target genes [5, 6]. TP63 encodes three main splice variants, TAp63a, TAp63 $\beta$ and TAp63 $\gamma$, which differ in their carboxytermi-

\section{KARGER 125}

(c) 2015 S. Karger AG, Base

$1015-2008 / 15 / 0824-0166 \$ 39.50 / 0$
Bence Kővári

Department of Pathology

University of Szeged

Állomás u. 2, HU-6720 Szeged (Hungary)

www.karger.com/pat 
nal domains, and $\Delta \mathrm{Np} 63$, also known as $\mathrm{p} 40$ isoforms, resulting from alternative promoter usage which lack the $\mathrm{N}$-terminal (transcription activation, TA) domain [7]. TAp63a and TAp63 $\gamma$ trigger an antiproliferative effect rendering them tumor suppressor proteins, whereas the p40 isoform works as an oncoprotein and suppresses the transactivation activity of both TAp63 and p53 [8].

p63 is expressed in basal epithelia in a restricted pattern, and is utilized primarily as a marker of squamous [9], myoepithelial (MEC) [10], prostate basal [11] and urothelial cells [12] in current surgical pathology practice.

In comparison to other MEC markers, p63 is slightly less sensitive but more specific than smooth muscle actin (SMA), smooth muscle myosin heavy chain (SMMHC) and calponin [13].

p40 is the newest member of the family being used as an immunohistochemistry (IHC) marker and is reported to be superior to $\mathrm{p} 63$ for squamous differentiation in the differential diagnosis of non-small cell lung cancer [14].

In this study, we analyzed a series of breast lesions with occasional absence of or decrease in the staining for some MEC markers [15-17] for the expression of p40 and correlated the results to the $\mathrm{p} 63$ staining profile. We investigated whether there was a difference in the expression of the two proteins and whether $\mathrm{p} 40$ was superior to $\mathrm{p} 63$ also as a MEC marker. In addition, samples of no special type (NST; ductal) invasive carcinomas negative for estrogen receptor, progesterone receptor and HER2 (human epidermal growth factor receptor 2), i.e. triple-negative carcinomas expressing cytokeratin 5 (CK5), were also included in the study, and their expression of p63 versus p40 was compared.

\section{Materials and Methods}

Groups of different histological types of breast lesions documented to demonstrate occasional alteration in MEC phenotype, including benign sclerosing lesions, ductal carcinoma in situ (DCIS) and adenomyoepithelial lesions were selected, and associated normal breast tissue was also analyzed.

Tissue blocks were mainly obtained from the archives of the Department of Pathology, Bács-Kiskun County Teaching Hospital, and the University of Szeged, but for adenomyoepithelial lesions, blocks were also obtained from the Department of Pathology, University Hospital Center Sestre Milosrdnice, Zagreb, and the Second Department of Pathology of the Semmelweis University, Budapest. The cases were randomly selected on the basis of their diagnoses. All blocks were from breast surgical resection specimens.

Randomly selected consecutive triple-negative breast carcinomas expressing high-molecular-weight CK5, corresponding to a subset of basal-like carcinomas on the basis of the surrogate IHC approach described by Nielsen et al. [18], were used to build up a double tissue microarray (TMA) consisting of 20 carcinomas in duplicate cores $2.2 \mathrm{~mm}$ in diameter. The cores were taken from the periphery of the tumors as much as possible to avoid the central necrotic areas often present in these cancers. Two orientation markers of nonmammary tissues (liver and kidney, serving as negative controls) were also included, and at least one of the cores was taken from a part of the tumor including normal lobules or ducts to serve as positive controls for myoepithelial markers. One sample was consistently damaged and uninterpretable on all slides and in both cores, and was therefore excluded from all analyses [19].

Tissues were fixed in neutral buffered formalin and embedded in paraffin. (TMA were also built up from such tissue blocks.) Whole tissue sections ( $4-5 \mu \mathrm{m}$ thick) were used for IHC, except for the CK5-expressing carcinomas accumulated in TMA.

The following mouse monoclonal antibodies were used for IHC: ACI 3066 (clone BC28) anti-p40 (BioCare, Concord, Calif., USA) and MS-1081 (clone 4A4) anti-p63 (LabVision NeoMarkers, Fremont, Calif., USA). The former (with a synthetic peptide corresponding to amino acids 5-17 of human p40 as immunogen) is stated to selectively recognize the $\mathrm{p} 40$ isotype of $\mathrm{p} 63$, whereas the latter (with amino acids 1-205 incorporating the TA domain as immunogen) is stated to recognize all isotypes of p63 (being a 'panp63' marker) according to the respective manufacturer's data sheets provided with the antibodies.

Deparaffinization and rehydration at room temperature were followed by antigen retrieval with the PT Link system (10 mM sodium citrate buffer, $\mathrm{pH}$ 6.0, for $30 \mathrm{~min}$ at $94^{\circ} \mathrm{C}$; Dako, Glostrup, Denmark). After being rinsed with Tris-buffered saline (EnVision FLEX Wash), the sections were placed in a Dako Autostainer Link 48 for endogenous peroxidase blockage and staining. Diaminobenzidine or VIP (Vector Laboratories, Burlingame, Calif., USA) was used as chromogen. The sections were then counterstained with Mayer's hematoxylin, dehydrated, cleared in xylene and mounted. Negative controls were carried out by omitting the primary antibody.

All specimens were evaluated by two pathologists (B.K. and G.C.) in parallel using a double-headed microscope.

The institutional ethical committee of the Bács-Kiskun County Teaching Hospital was consulted and this noninterventional study was approved.

\section{Results}

Thirty-four breast lesions were included in the present study, and healthy terminal ductal lobular units (TDLU) were also evaluated in each case, where available on the selected slide $(\mathrm{n}=31)$. The evaluated breast lesions were as follows: 10 adenomyoepithelial lesions [including 9 adenomyoepitheliomas (AME) and 1 adenomyoepithelial adenosis], 13 high-grade DCIS with attenuated/flattened MEC layer and 11 sclerosing lesions (including 10 complex sclerosing lesions and 1 complex fibroadenoma with areas of sclerosing adenosis). Nineteen CK5-expressing triple-negative breast carcinomas were additionally assessed. 
Fig. 1. Parallel p40 (a, c) and p63 (b, d) staining patterns of MEC around DCIS and in AME. a, b DCIS with scant, flattened, IHC-positive MEC highlighted with asterisks (top left of each panel) and without IHC-positive MEC (lower left of each panel); note the contrasting strong and diffuse staining of MEC around normal structures (right of each panel). c, d AME with rather diffuse and strong staining with both markers. a-d $\times 40$.

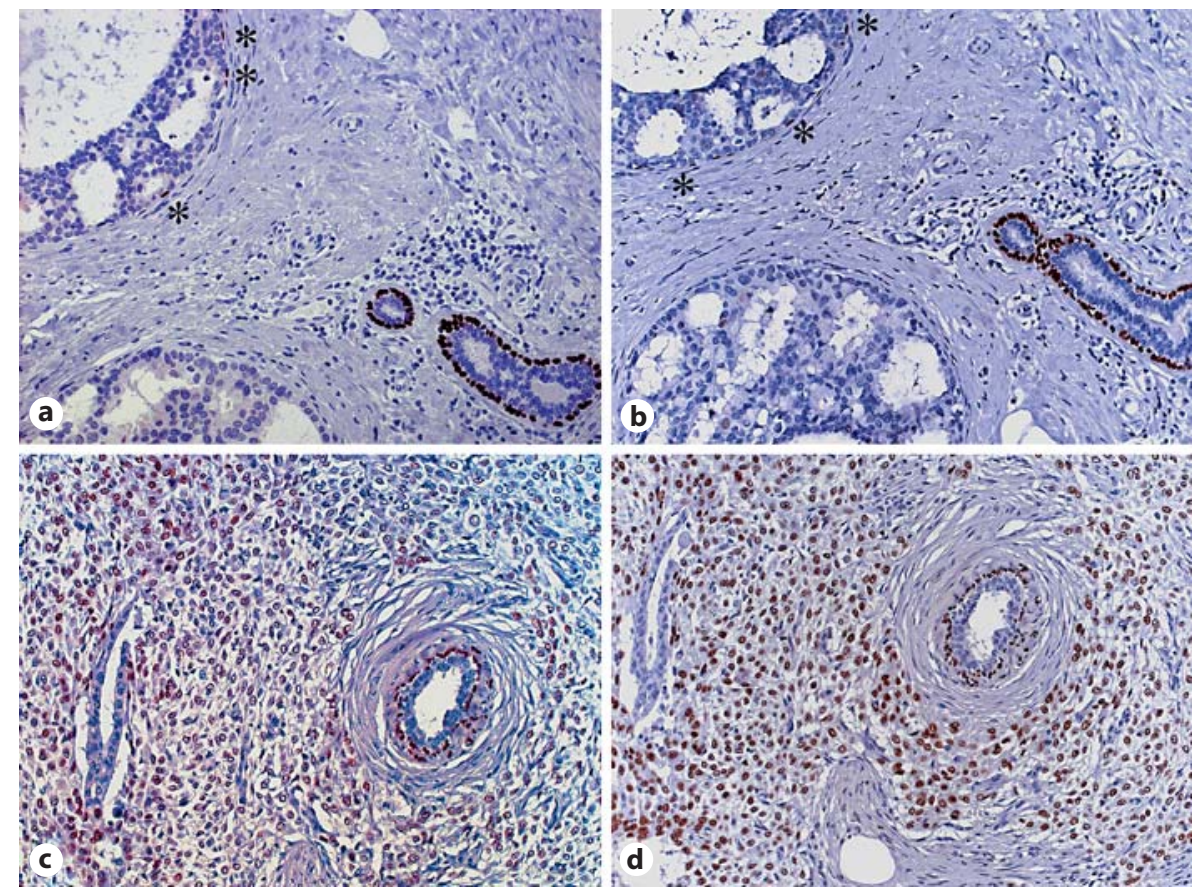

In all the cases, where appropriate (31/31), a general diffuse strong nuclear $\mathrm{p} 40$ positivity was detected in normal TDLU around the lesions. p40 and p63 staining patterns showed no difference in regular TDLU (fig. 1a, b).

All adenomyoepithelial lesions showed nuclear $\mathrm{p} 40$ positivity in the MEC component ranging from weak focal $(5 / 10)$ to strong diffuse $(5 / 10)$. No conspicuous difference between $\mathrm{p} 40$ and $\mathrm{p} 63$ reactivity was noted (fig. 1c, d).

The attenuated/flattened MEC around DCIS showed somewhat weaker nuclear staining compared with surrounding normal TDLU, and negative cells with unequivocal MEC morphology were also detectable (fig. 1). Rarely, ducts affected by DCIS showing no positivity of the MEC were also recognized. In this set of lesions, MEC stained practically in an identical manner with p40 and p63. In 2 cases, focal positivity (few cells in an estrogen receptor- and progesterone receptor-negative but HER2overexpressing in situ carcinoma and up to $10 \%$ in a triple-negative one) was detected in the epithelial cells of the DCIS using p40 IHC, whereas p63 staining was weaker in the first and barely perceptible (requiring high-power inspection for detection) in the second case.

All 11 sclerosing lesions displayed p40 positivity of inconstant intensity, which was usually weaker than in the endogenous normal TDLU serving as control. Focally negative MEC were also visible in multiple cases. The p63 and $\mathrm{p} 40$ reactions were again identical in pattern and intensity (fig. 2).

Of the 19 CK5-expressing triple-negative breast carcinomas, 8 showed some $\mathrm{p} 63$ positivity, ranging from a few cells to $70 \%$ of the tumor cells. The intensity was generally weak and detection required scrutinous search; the intensity of staining was strong in 1 case only (fig. 3b). In contrast, p40 positivity could be seen in the majority of the cases $(18 / 19)$ ranging from a few cells $(<1 \%)$ to $70 \%$. The intensity was either similar to that seen with p63 or stronger (fig. 3).

\section{Discussion}

The identification of an outer MEC layer is a valuable clue in the differential diagnosis of breast lesions. A broad spectrum of different cytoplasmic (e.g. SMA, SMMHC, calponin, S100 or CK5/CK6), nuclear (e.g. S100 and p63) and membranous (e.g. CD10) MEC markers is used by reporting pathologists.

p63 protein is a commonly used MEC marker. Due to its high sensitivity (90\%) and even superior specificity (up to $100 \%$ in normal TDLU) reported [10], it is preferred to cytoplasmic markers (SMA, calponin and SMMHC), as the latter may also react with vascular smooth muscle cells and myofibroblasts [13]. The specificity of p63 is 
Fig. 2. Staining of MEC with $\mathrm{p} 40$ (a, c) and p63 (b, d) in sclerosing lesions. MEC are nicely highlighted with the two stains in both the distorted sclerosing glands $(\mathbf{a}, \mathbf{b}$ : top right area) and the nondistorted glands (elsewhere), but show parallel diminished staining around the centrally located apocrine glands. $\mathbf{a}, \mathbf{b} \times 20$. c, $\mathbf{d} \times 40$.

Fig. 3. Staining of CK5-expressing carcinoma cells with p40 (a, c) and p63 (b, d). a, b Similar staining in the case demonstrating the most labeled cells and the strongest positivity with both antibodies. Staining of some cells with p40 (c) and lack of staining with p63 (d) in another case. a, $\mathbf{b} \times 5$. c, $\mathbf{d} \times 200$ (from digital slides).
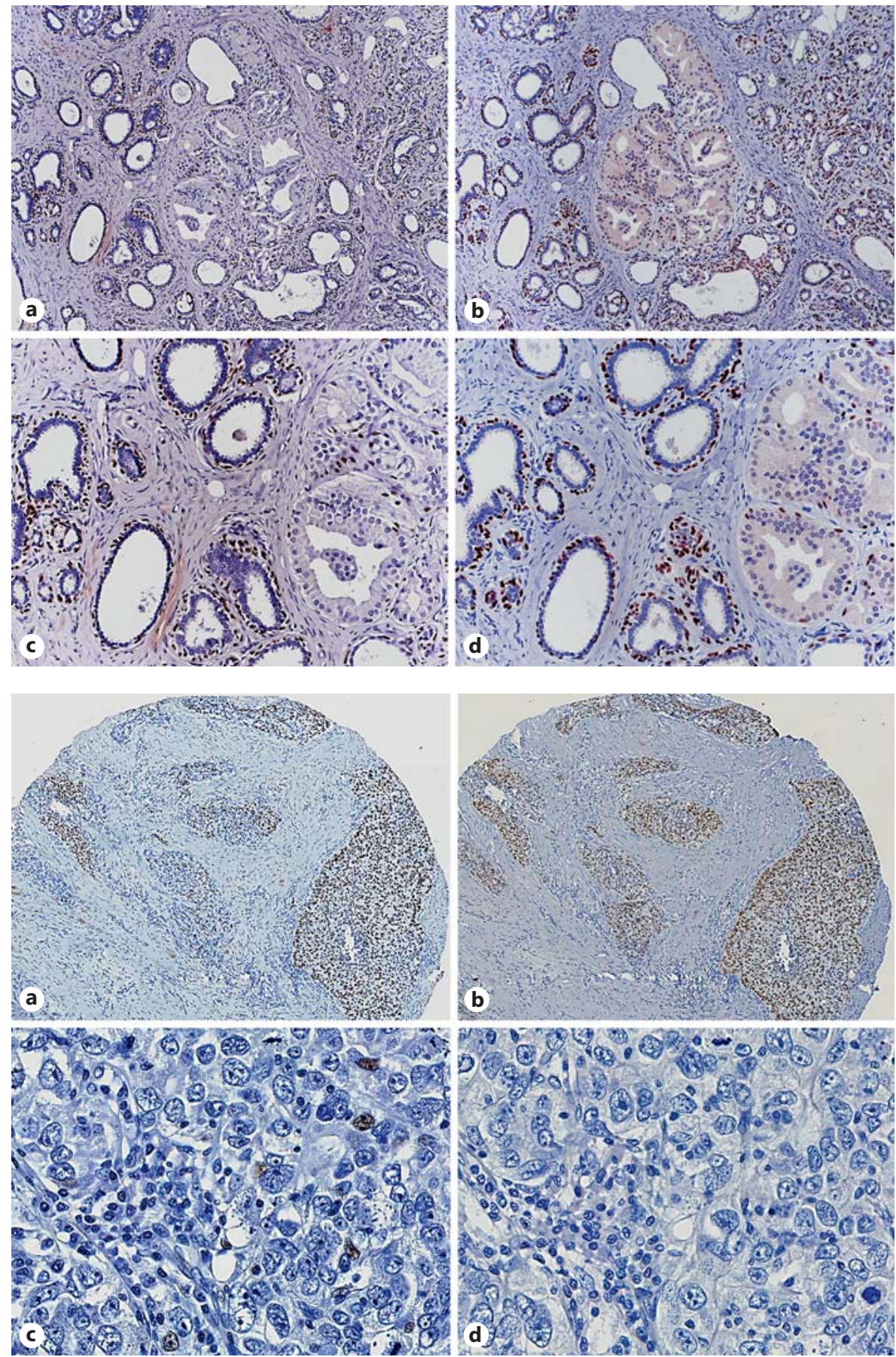

somewhat diminished by the observation that it is rarely expressed by tumor cells of NST carcinomas [13].

Reduced expression of markers in MEC associated with DCIS and complex sclerosing lesions is a documented phenomenon $[15,16]$, and such an alteration in the MEC phenotype has also been reported in AME [17]. Some markers (CD10, CK5/6 and SMMHC) show reduced expression more frequently than others (p63, SMA and calponin) $[15,16]$. This study specifically focused on lesions that have been reported to demonstrate an altered MEC phenotype, i.e. a change in the expression of MEC markers compared with MEC of the normal breast parenchyma: 
sclerosing lesions [15], high-grade DCIS [16] and adenomyoepithelial lesions [17]. Our results suggest that p63 and p40 perform similarly in all these settings. In normal breast tissue, MEC are nicely highlighted by both antibodies, and when the expression of one is reduced in a pathological condition, the other shows a similar reduction in expression; focal losses of expression occurred in parallel.

Although $\mathrm{p} 40$ has been reported to have superior specificity than p63 as a squamous cell carcinoma marker in the differential diagnosis of non-small cell lung cancer [14], it seems to perform similarly in breast lesions acknowledged to show altered expression of MEC markers. It is, therefore, suggested that both antibodies can be used interchangeably for the demonstration of MEC. One obvious difference between the staining patterns of p63 and p40 is the higher proportion of focal positivity in carcinoma cells. Whether this phenomenon is restricted or preferential in basal-like carcinomas expressing CK5 has not been examined, but CK5-expressing triple-negative carcinomas seem to express p40 frequently, and one of the DCIS cases showing a few p40- and p63-positive cells was a HER-2-overexpressing lesion.

A recent study performing a TMA analysis of a larger number of breast lesions [32 adenoses, 34 intraductal papillomas, 31 DCIS, 257 (ductal) NST carcinomas and 36 metaplastic carcinomas] with monoclonal pan-p63 and polyclonal p40 antibodies from different sources (but with an identical clone and identical target epitopes, respectively) reached a similar conclusion regarding the corresponding staining of MEC with p63 and p40 antibodies [19]. However, despite the identical epitopes used to generate the polyclonal p40 antibodies, one of the two tested (Diagnostic Biosystems, Pleasanton, Calif., USA) showed a much higher proportion of cancer cell labeling, highlighting the different sensitivities and specificities of the two antisera. This latter antibody was also less specific for MEC in DCIS. On the basis of the surrogate IHCbased molecular classification, the highest proportion of p63 or p40 staining was found in triple-negative carcinomas [19]. Identical staining of MECs with monoclonal p63 and p40 antibodies was also reported in a small series of 10 breast excision specimens [20].

The fact that the p63 antibody we used (a pan-p63 marker) should theoretically label more cases than the p40 antibody identifying only the $\Delta \mathrm{Np} 63$ isoforms makes our finding of a higher rate of cancer cell labeling with $\mathrm{p} 40$ somewhat enigmatic. The explanation may perhaps lie in the differences in sensitivities alluded to in the previous paragraph in connection with two polyclonal p40 antibodies. However, the small sample size, a limitation of the present study, may also play a role.

In conclusion, p40 seems to be similar to p63 as an MEC marker both in normal breast tissue and in lesions with observed alterations in the MEC immunophenotype. The presence of tumor cell positivity in NST carcinomas demonstrating an IHC staining profile mostly in keeping with a basal-like molecular subtype did not interfere with MEC detection but should be acknowledged, and the preference of $\mathrm{p} 40$ for highlighting this subset of carcinomas rather than other subtypes should be further investigated.

\section{Acknowledgment}

B.K. was supported by the TÁMOP-4.2.2.A-11/1/KONV2012-0035 project. A.M.S. was supported by the European Union and the State of Hungary, co-financed by the European Social Fund in the framework of TÁMOP 4.2.4.A/2-11-1-2012-0001 'National Excellence Program'. G.C. was supported by a grant from the University of Szeged (KEP 2014).

\section{References}

$>1$ Kaghad M, Bonnet H, Yang A, Creancier L, Biscan JC, Valent A, Minty A, Chalon P, Lelias JM, Dumont X, Ferrara P, McKeon F, Caput D: Monoallelically expressed gene related to $\mathrm{p} 53$ at $1 \mathrm{p} 36$, a region frequently deleted in neuroblastoma and human cancers. Cell 1997;90:809-819.

-2 Osada M, Ohba M, Kawahara C, Ishioka C, Kanamaru R, Katoh I, Ikawa Y, Nimura Y, Nakagawara A, Obinata M, Ikawa S: Cloning and functional analysis of human p51, which structurally and functionally resembles p53. Nat Med 1998;4:839-843.
3 Levine AJ: p53, a cellular gatekeeper for growth and division. Cell 1997;88:323-331.

$\checkmark 4$ Wang XW, Harris CC: p53 tumor-suppressor gene: clues to molecular carcinogenesis. J Cell Physiol 1997;173:247-255.

5 Yang A, Schweitzer R, Sun D, Kaghad M, Walker N, Bronson RT, Tabin C, Sharpe A, Caput D, Crum C, McKeon F: p63 is essential for regenerative proliferation in limb, craniofacial and epithelial development. Nature 1999;398:714-718.
6 Shimada A, Kato S, Enjo K, Osada M, Ikawa Y, Kohno K, Obinata M, Kanamaru R, Ikawa $\mathrm{S}$, Ishioka C: The transcriptional activities of p53 and its homologue p51/p63: similarities and differences. Cancer Res 1999;59:27812786.

7 Little NA, Jochemsen AG: p63. Int J Biochem Cell Biol 2002;34:6-9.

8 Senoo M, Matsumura Y, Habu S: TAp63gamma (p51A) and dNp63alpha (p73L), two major isoforms of the p63 gene, exert opposite effects on the vascular endothelial growth factor (VEGF) gene expression. Oncogene 2002; 21:2455-2465. 
9 Kargi A, Gurel D, Tuna B: The diagnostic value of TTF-1, CK 5/6, and p63 immunostaining in classification of lung carcinomas. Appl Immunohistochem Mol Morphol 2007;15: 415-420.

10 Barbareschi M, Pecciarini L, Cangi MG, Macrì $\mathrm{E}$, Rizzo $\mathrm{A}$, Viale $\mathrm{G}$, Doglioni C: p63, a p53 homologue, is a selective nuclear marker of myoepithelial cells of the human breast. Am J Surg Pathol 2001;25:1054-1060.

-11 Signoretti S, Waltregny D, Dilks J, Isaac B, Lin D, Garraway L, Yang A, Montironi R, McKeon F, Loda M: p63 is a prostate basal cell marker and is required for prostate development. Am J Pathol 2000;157:1769-1775.

12 Srinivasan M, Parwani AV: Diagnostic utility of p63/P501S double sequential immunohistochemical staining in differentiating urothelial carcinoma from prostate carcinoma. Diagn Pathol 2011;6:67.
13 Werling RW, Hwang H, Yaziji H, Gown AM: Immunohistochemical distinction of invasive from noninvasive breast lesions: a comparative study of p63 versus calponin and smooth muscle myosin heavy chain. Am J Surg Pathol 2003;27:82-90.

14 Bishop JA, Teruya-Feldstein J, Westra WH, Pelosi G, Travis WD, Rekhtman N: p40 $(\Delta \mathrm{Np} 63)$ is superior to p63 for the diagnosis of pulmonary squamous cell carcinoma. Mod Pathol 2012;25:405-415.

15 Hilson JB, Schnitt SJ, Collins LC: Phenotypic alterations in myoepithelial cells associated with benign sclerosing lesions of the breast. Am J Surg Pathol 2010;34:896-900.

16 Hilson JB, Schnitt SJ, Collins LC: Phenotypic alterations in ductal carcinoma in situ-associated myoepithelial cells: biologic and diagnostic implications. Am J Surg Pathol 2009; 33:227-232.
17 Hayes MM: Adenomyoepithelioma of the breast: a review stressing its propensity for malignant transformation. J Clin Pathol 2011; 64:477-484.

18 Nielsen TO, Hsu FD, Jensen K, Cheang M, Karaca G, Hu Z, Hernandez-Boussard T, Livasy C, Cowan D, Dressler L, Akslen LA, Ragaz J, Gown AM, Gilks CB, van de Rijn M, Perou CM: Immunohistochemical and clinical characterization of the basal-like subtype of invasive breast carcinoma. Clin Cancer Res 2004; 10:5367-5374

19 Kim SK, Jung WH, Koo JS: p40 ( $\Delta$ Np63) expression in breast disease and its correlation with p63 immunohistochemistry. Int J Clin Exp Pathol 2014;7:1032-1041.

20 Sarda R, Taylor J: p40 ( $\Delta$ Np63), a lung squamous cell marker, can also be used to label breast myoepithelial cells. Arch Pathol Lab Med 2014;138:584. 